\title{
Patterns of compensation of functional deficits of the knee joint in patients with juvenile idiopathic arthritis
}

\author{
Beata Żuk ${ }^{1}$, Krystyna Księżopolska-Orłowska \\ ${ }^{1}$ Department of Biophysics and Physiology, Medical Faculty, Medical University of Warsaw, Warsaw, Poland \\ ${ }^{2}$ Department of Rheumatologic Rehabilitation, Institute of Rheumatology, Warsaw, Poland
}

\begin{abstract}
Objectives: Juvenile idiopathic arthritis (JIA) is a group of pathological syndromes of unknown aetiology, observed at the developmental age. Their common feature is sustained chronic arthritis with flares and remissions. Clinical signs and symptoms include joint pain, periarticular tissue oedema or articular exudate, frequently associated with hypertrophy of the synovial membrane. The intra- and extra-articular structural damage impairs the motion range and smoothness. The disease process may involve any joint. The knee joint is the most frequently affected in oligo- and polyarthritis. The aim of the study was to determine a direct correlation between disorders of knee joint function and the change in the range of motion of the ankle and hip joints of both lower extremities, and the so-called indirect impact of these changes on patients' posture.

Material and methods: The study included 36 JIA patients and 56 healthy controls aged 8-16 years. The evaluation was based on physical examination.

Results: The results showed differences in the values of quality and range of motion between patients and controls. In the patient group pes planovalgus was more frequently associated with knee joint dysfunction along with the inherent restriction of dorsal flexion of the foot. Shortening of the iliotibial band, increased outward rotation of the right lower extremity with enlarged joint contour and augmented inward rotation of the contralateral healthy extremity all proved significant. Changes in motion range in the joints below and over the knee were associated with alterations of antero-posterior spine curvatures and vertebral rotation along the long spinal axis. Based on the results, the mechanism of the compensation is outlined.

Conclusions: The observed differences in the range and quality of motion in the ankle, hip and spinal joints between patients and healthy children provide evidence that dysfunction of the knee joint affects the function of the other above-mentioned levels of the motor system.
\end{abstract}

Key words: juvenile idiopathic arthritis, compensation, knee joint.

\section{Introduction}

Juvenile idiopathic arthritis (JIA) is a group of immunoinflammatory diseases where the common characteristic is chronic arthritis. The following diagnostic criteria were assumed: age under 16 years, symptoms of arthritis lasting at least 6 weeks and elimination of other diseases [1, 2]. Apart from pain, clinical signs of JIA are pathological changes in the structures of the joints.
They impair the joints' range of motion and fluidity. Concomitant muscular atrophy worsens functional efficiency of the child. The inflammatory process may affect any joint, but it usually occurs in peripheral joints. The knee joint takes the first place in respect of the occurrence of disorders in oligo- and polyarthritis [3, 4].

The aim of the study was to determine a direct correlation between disorders of knee joint function and the change in the range of motion of the ankle and hip

Address for correspondence:

Beata Żuk, Department of Biophysics and Physiology, Medical Faculty, Medical University of Warsaw, Chałubińskiego 5, 02-004 Warsaw,

Poland, e-mail: beata-zuk@o2.pl

Submitted: 3.06.2015; Accepted: 26.08.2015 
joints of both lower extremities, and the so-called indirect impact of these changes on the patients' posture.

\section{Material and methods}

\section{Patients}

Overall 36 patients, aged $8-16$, including 21 with oligoarthritis (up to 4 joints involved) and 15 with polyarthritis (number of involved joints 5 or more), treated in the Institute of Rheumatology, Warsaw, were included in the study. Disorders of knee joint function - according to medical documentation (the result of an ultrasound examination) and measurements of the circumference through the patella - were distributed in the following way: in 12 individuals (33.3\%) the right knee joint was affected, in 11 (30.6\%) the left knee joint, in 13 (36.1\%) both joints, with a predominance of exudate/oedema in one of them. Other arthritic deformations were observed only in hand joints. The reference group comprised 56 children matched for age. Approval for the study from the Bioethics Commission of the Institute of Rheumatology in Warsaw (decision of 29 October 2009) was obtained. The children's parents gave written consent to the examination of the motor system.

Inclusion criteria for the study were the following: diagnosis of JIA with detailed form of the disease, determined drug treatment not altered for the previous two weeks, changes in the knee joint with pain, oedema, exudate and movement restriction. Exclusion criteria in cluded: contracture in flexion above $10^{\circ}$, limited flexion in the joint above $100-110^{\circ}$, alleged valgus deformity of one of the knee joints that occurred during the course of JIA, physiological valgity of the knee joint (above $15^{\circ}$ ), the valgity of the feet above $2^{\circ}$ and inflammatory changes in the adjacent joints, i.e. metatarsophalangeal joints, in the upper and lower tarsal joints, hip joints (positive Thomas test), scoliosis, vision defect and hearing impairment. The children excluded from the control group during physical examination were diagnosed with different absolute length of the lower extremities, vertebral rotation above $4^{\circ}$, scoliosis, other orthopaedic disorders, vision defect and hearing impairment.

\section{Methods}

Physical examination of the two groups of children included linear measurement of the lower extremities, anterior and posterior spinal curvatures, vertebral rotation, the evaluation of deviation of posterior projection of the vertical in body posture, measurements of active range of motion in the hip and ankle joints, and evaluation of the elasticity of the iliotibial band. The examination started with an easy sitting position, i.e. with the knee joints extended, the feet kept about anterior superior iliac spines-width apart, the heels in one line. To assess physiological curvatures of the vertebral column, a Rippstein plurimeter was used. Spinous processes - C7/Th1 for the value of thoracic kyphosis and L5/ S1 for the value of lumbar lordosis - were determined on the patients' body. To measure the angle of kyphosis, the plurimeter was adjusted to 'zero' position at the level of Th12. Measurements were made twice, within an accuracy of $5^{\circ}$, at the beginning of the examination and when it was finished (maximal time did not exceed 15 minutes). Posterior projection of the vertical was assessed in a standing position, behind the frontal plane. In the same initial position, using the Adam forward bend test, vertebral rotation of particular segments of the vertebral column was assessed. To measure the angle of rotation of Th3, Th7, Th12, L2/3, the Bunnell scoliometer was used [5].

In this position the values of angle of trunk rotation measured in degrees were read off. In a standing position backwards, the positioning of the left and right foot in four categories was assessed: correct, flat, flat-valgus and talipes varus. Functional evaluation of a flat-valgus foot was made using the Seyfried test, with the patient standing on the examined extremity. The following degrees of disorders were distinguished: first degree - in a load position, while turning the trunk inside and outside, the foot is pronating and supinating, the first head of the metatarsal bone during pronation is adhering to the floor; second degree - the foot is slightly deformed or stays stiff; third degree - considerable movement restriction, with load the foot stays stiff [6]. Then linear measurements were made using a measuring tape. In a supine position (solely in the group of patients) the circumference of the knee joints through the knee joint and $10 \mathrm{~cm}$ above the base of the patella was measured. In the same supine position, the range of active extension in the ankle was determined using a Rippstein plurimeter. The base of the plurimeter was placed on the sole of the foot, on its external side; $90^{\circ}$ was assumed as an initial position (zero). The child was asked to make maximal active extension (dorsal flexion) of the foot with a complete extension of the knee joint.

The next stage was the evaluation of elasticity of the iliotibial band, which was performed using the Ober test. It is performed with the patient lying on the side. The therapist lifts the lower limb flexed at the knee joint to an angle of $90^{\circ}$ when contracture of the fascia adduction is impossible. The range of motion of active internal and external rotation of the hip joints was measured using a Rippstein plurimeter, in two positions: prone and sitting. In a prone position, the thigh was in the frontal 
plane, the hip joints were extended, knee joints bent to the angle of $90^{\circ}$. The pelvis in the position $0^{\circ}$ was stabilised with the hand of the examiner placed on the sacral bone. According to Kotwicki et al. [7], the pelvis in the position $0^{\circ}$ was put using a scoliometer, whose arms were placed along the line of the posterior superior iliac spines. The next measurements were taken in a sitting position on an examination table: the thigh in the frontal plane, the knee and hip joints bent to an angle of $90^{\circ}$. Special attention was paid to a full load of both ischiadic tubers (the child was informed about how to sit, that it is important not to stabilize the pelvis in this position and tried to cooperate with the person performing the examination). The child's hands were lying loosely on the examination table.

Statistical analysis was conducted using SAS 9.2. (SAS, Institute Inc, Cary, NC, USA). The results of quantitative variables were expressed in the form of arithmetic means and standard deviations (variables of normal distributions) or in the form of median and minimal and maximal values (other distributions: duration of disease). Categorical data (nominal and ordinal) were presented as absolute frequency and relative frequency (percentage) of distinguished units. The compliance of distribution of quantitative variables with normal distribution was assessed using the Shapiro-Wilk test. To compare the significance of differences between mean values of two independent groups of variables with normal distribution (or the obliquity coefficient $<1$ ), depending on homogeneity or heterogeneity of variance, the Student t-test or Cochran-Cox test was used respec-

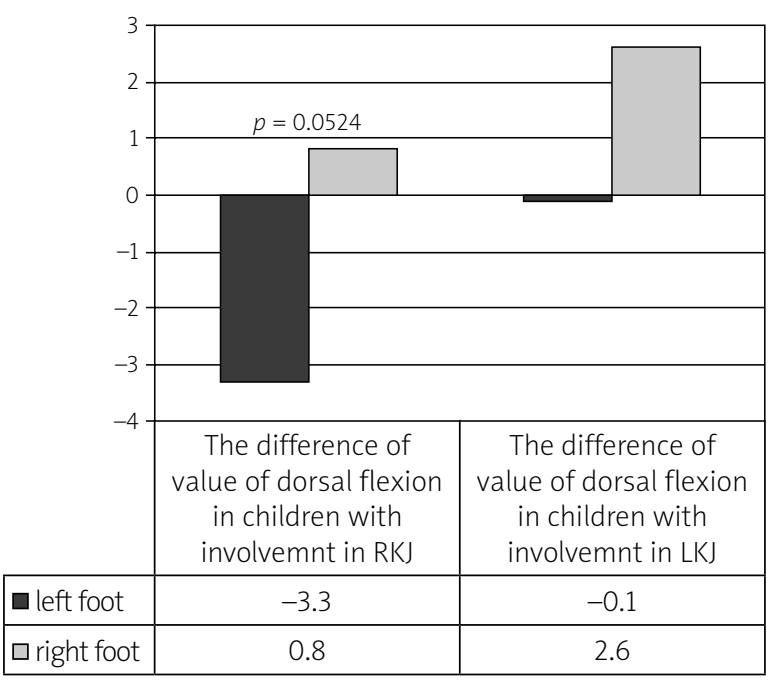

RKJ - right knee joint, LKJ - left knee joint

Fig. 1. Differences of dorsal flexion of the feet in patients with left and right knee joint involvement vs. healthy controls. tively. Homogeneity of variance was analysed using the Fisher test. In the case of deviations from the norm, to verify null hypotheses, the non-parametric Mann-Whitney test was applied. The significance of differences between dependent measurements was analysed using the Student's paired $t$ test or nonparametric Wilcoxon signed rank test. Linear correlation between quantitative traits was assessed using Pearson's (two normal traits) or Spearman's (at least one trait of unknown distribution) correlation coefficient. Nominal variables were examined using contingency tables. The distribution of traits was analysed with Pearson's $\chi^{2}$ test and Yates' correction for continuity. In cases when the expected value of observation in the section was less than 5, additionally, Fisher's exact test was used. The verification of null hypotheses was conducted with statistical significance assumed at the level of $\alpha \leq 0.05$. Bilateral testing was applied.

\section{Results}

In the two groups, the types of feet were evaluated in three categories - two correct feet, one foot incorrect, and both feet incorrect - assuming that an incorrect foot may be flat, flat-valgus or talipes varus. A statistically significant difference between the study group and the reference group was found $(p<0.0005)$. A definite majority of paediatric patients had two incorrect feet $(n=29 ; 80.6 \%)$. There was no case with one incorrect foot, which did occur in healthy controls ( $n=14 ; 25.0 \%)$. Differences between the foot type in patients and healthy controls were found, particularly for the right foot. Young patients had markedly more frequently the right foot flat-valgus ( $n=19 ; 52.8 \%)$ than the left one $(n=15 ; 41.7 \%)$, whereas in healthy controls opposite results were noted.

Active range of motion of dorsal flexion of the right and left foot was measured in the study subjects. In the group of patients with only right knee joint involvement $(n=12)$, a slight difference in dorsal flexion between the right and left foot was observed, with predominance of a greater value of active dorsal flexion in the left foot. In the group of patients with left knee joint involvement $(n=11)$, the values of differences in active dorsal flexion of the left and right foot are nearly half the value of that in the children with dysfunction in the right knee joint (Fig. 1).

The changes in the values of active dorsal flexion of the right and left foot were examined depending on the foot types, in three categories: correct foot, flat, and flat-valgus foot (cases of talipes varus were excluded). In the group of healthy children, decreasing values of active dorsal flexion of the feet together with different foot type were observed ( $p=0.0080)$. A different cor- 
relation was observed in the group of young patients, compared to healthy controls. The children with correct feet had the smallest dorsal flexion of the foot $(p=0.0267)$. The comparison of the values of active range of motion of internal and external rotation in the hip joints was made separately for the two groups of young patients - those with right knee joint dysfunction and those with left knee joint dysfunction. The patients with disorders of function of two knee joints were excluded from the analysis. Table I presents the differences in rotation between the group of patients with right knee joint involvement and the group of healthy controls, and the differences in rotation between the patients with left knee joint involvement and healthy controls are shown in Table II.

In the case of right knee joint dysfunction, internal and external rotations in the right and left hip joints, and the sum of these rotations, are different from respective values in the healthy children. The exception is internal rotation of the left hip joint (i.e. of the lower extremity without knee joint involvement) in a supine position. Similarly, a relatively small difference for the same rota- tion of the left hip in a sitting position is observed (the threshold of statistical significance, $p=0.0232$ ).

In sitting and recumbent positions, internal rotations of the right and left hip joint, in the case of left knee joint dysfunction, are similar to the value of rotation observed in healthy controls (from -3.2 to -4.5 ). Slightly bigger differences of the sum of rotations for the left side (-21.6 and -21.5$)$, compared to the right side (-18.6; -18.8), were observed (Table II). Shortening of the iliotibial band (positive result of the Ober test) was found only in the group of patients $(p<0.0001)$. Smaller elasticity of the iliotibial band was found in 20 (55.6\%) children in the right lower extremity and in $16(44.4 \%)$ in the left lower extremity. Deviations of the posterior projection of the vertical were evaluated in three categories: lack of deviation, deviation to the right or deviation to the left. The shift of the vertical to the left was found statistically significantly more often $(<0.0001)$ - almost four times in the young patients (55.6\%), compared to healthy controls (14.3\%). The shift of the posterior projection of the vertical to the right was found slightly more frequently in the patients than in healthy controls ( $8.3 \%$ vs. $5.4 \%$ ),

Table I. Difference in internal and external rotation in the hip joints in patients with right knee joint involvement, compared to internal and external rotation in the hip joints in healthy controls

\begin{tabular}{|c|c|c|c|c|}
\hline $\begin{array}{l}\text { Paediatric patients with involvement } \\
\text { in the right knee joint }\end{array}$ & $\begin{array}{l}\text { Paediatric patients } \\
\qquad n=12\end{array}$ & $\begin{array}{l}\text { Healthy children } \\
n=56\end{array}$ & $\begin{array}{l}\text { Difference vs. } \\
\text { healthy children }\end{array}$ & $p$ \\
\hline \multicolumn{5}{|l|}{ Right hip joint } \\
\hline \multicolumn{5}{|l|}{ Sitting position } \\
\hline Internal rotation & $29.6 \pm 8.6$ & $38.7 \pm 8.3$ & $-9.1 \pm 8.3$ & 0.0011 \\
\hline External rotation & $35.0 \pm 10.7$ & $50.6 \pm 5.4$ & $-15.7 \pm 6.1$ & 0.0003 \\
\hline Sum of rotations & $64.6 \pm 8.9$ & $89.3 \pm 9.8$ & $-24.7 \pm 9.7$ & $<0.0001$ \\
\hline \multicolumn{5}{|l|}{ Recumbent position } \\
\hline Internal rotation & $30.8 \pm 9.5$ & $42.6 \pm 7.3$ & $-11.8 \pm 7.3$ & $<0.0001$ \\
\hline External rotation & $41.3 \pm 10.9$ & $50.5 \pm 7.9$ & $-9.3 \pm 8.5$ & 0.0010 \\
\hline Sum of rotations & $72.1 \pm 7.5$ & $93.1 \pm 11.7$ & $-21.0 \pm 11.1$ & $<0.0001$ \\
\hline \multicolumn{5}{|l|}{ Left hip joint } \\
\hline \multicolumn{5}{|l|}{ Sitting position } \\
\hline Internal rotation & $32.9 \pm 10.5$ & $39.2 \pm 8.0$ & $-6.3 \pm 7.5$ & 0.0232 \\
\hline External rotation & $33.3 \pm 7.8$ & $51.1 \pm 5.7$ & $-17.7 \pm 6.1$ & $<0.0001$ \\
\hline Sum of rotations & $66.3 \pm 11.9$ & $90.3 \pm 10.3$ & $-24.0 \pm 10.6$ & $<0.0001$ \\
\hline \multicolumn{5}{|l|}{ Recumbent position } \\
\hline Internal rotation & $35.4 \pm 12.5$ & $43.1 \pm 7.5$ & $-7.7 \pm 8.6$ & 0.0609 (NS) \\
\hline External rotation & $37.5 \pm 6.6$ & $52.1 \pm 6.6$ & $-14.6 \pm 6.4$ & $<0.0001$ \\
\hline Sum of rotations & $72.9 \pm 13.0$ & $95.2 \pm 9.0$ & $-22.3 \pm 9.8$ & $<0.0001$ \\
\hline
\end{tabular}


Table II. Difference in internal and external rotation in the hip joints in patients with left knee joint involvement, compared to internal and external rotation in the hip joints in healthy controls

\begin{tabular}{|c|c|c|c|c|}
\hline $\begin{array}{l}\text { Paediatric patients with involvement } \\
\text { in the left knee joint }\end{array}$ & $\begin{array}{l}\text { Paediatric patients } \\
\qquad n=11\end{array}$ & $\begin{array}{l}\text { Healthy children } \\
\quad n=56\end{array}$ & $\begin{array}{l}\text { Difference vs. } \\
\text { healthy children }\end{array}$ & $p$ \\
\hline \multicolumn{5}{|l|}{ Right hip joint } \\
\hline \multicolumn{5}{|l|}{ Sitting position } \\
\hline Internal rotation & $35.5 \pm 9.3$ & $38.7 \pm 8.3$ & $-3.2 \pm 8.5$ & NS \\
\hline External rotation & $35.0 \pm 9.5$ & $50.6 \pm 5.4$ & $-15.6 \pm 6.2$ & 0.0002 \\
\hline Sum of rotations & $70.5 \pm 10.4$ & $89.3 \pm 9.8$ & $-18.8 \pm 9.9$ & $<0.0001$ \\
\hline \multicolumn{5}{|l|}{ Recumbent position } \\
\hline Internal rotation & $38.2 \pm 9.6$ & $42.6 \pm 7.3$ & $-4.4 \pm 7.7$ & NS \\
\hline External rotation & $36.4 \pm 9.0$ & $50.5 \pm 7.9$ & $-14.2 \pm 8.1$ & $<0.0001$ \\
\hline Sum of rotations & $74.5 \pm 11.1$ & $93.1 \pm 11.7$ & $-18.6 \pm 11.6$ & $<0.0001$ \\
\hline \multicolumn{5}{|l|}{ Left hip joint } \\
\hline \multicolumn{5}{|l|}{ Sitting position } \\
\hline Internal rotation & $35.9 \pm 8.3$ & $39.2 \pm 8.0$ & $-3.3 \pm 8.1$ & NS \\
\hline External rotation & $32.7 \pm 10.6$ & $51.1 \pm 5.7$ & $-18.3 \pm 6.7$ & 0.0002 \\
\hline Sum of rotations & $68.6 \pm 11.4$ & $90.3 \pm 10.3$ & $-21.6 \pm 10.5$ & $<0.0001$ \\
\hline \multicolumn{5}{|l|}{ Recumbent position } \\
\hline Internal rotation & $38.6 \pm 10.0$ & $43.1 \pm 7.5$ & $-4.5 \pm 8.0$ & NS \\
\hline External rotation & $35.0 \pm 11.2$ & $52.1 \pm 6.3$ & $-17.1 \pm 7.3$ & 0.0004 \\
\hline Sum of rotations & $73.6 \pm 13.1$ & $95.2 \pm 9.0$ & $-21.5 \pm 9.5$ & $<0.0001$ \\
\hline
\end{tabular}

but the difference was not significant. The comparison of physiological curvatures of the vertebral column in the sagittal plane showed a statistically significant difference in the values of curvatures at the level of C7/Th1 and L5/S1 between the patients and healthy controls $(p=0.0014)$. In the group of patients, the difference was $10.8 \pm 7.0$, in healthy controls $-6.2 \pm 5.2$. The correlation between the values of the angles of anteroposterior spinal curvatures are presented in Fig. 2. The lack of regression line indicates the lack of statistically significant correlation between the examined traits (statistically non-significant correlation different from 0 ).

The correlation between C7/Th1 and L5/S1 in the healthy children indicates that this dependence between the curvatures may be considered to be the norm. On this assumption, in the patients, deviation from the norm was observed. Vertebral rotations in an erect position in the patients and healthy controls were analysed. Rotations greater than 0 were assumed as incorrect. In the patients, statistically significantly greater vertebral rotation to the right occurred (Table III).

\section{Discussion}

Chronic and recurrent arthritis rarely threatens lives of young patients but may cause disability and lower the quality of life. Pleural effusion in the joint, synovial hypertrophy, morning stiffness and pain are characteristic of JIA. Mechanical effects of these disorders, compounded by potential changes in the articular cartilage, can lead to long-lasting or fleeting disturbance in the fascial-musculo-articular system. Muscle weakness, laxity of ligaments, and generalized or localized growth disturbances often contribute to the formation of internal compensation, whose aim is to prevent loss of function. A child with pathological changes in the knee joint, in order to be able to smoothly walk, is forced to activate an additional range of motion in the joints, i.e. the ankle joint and hip joint. And it uses the characteristic work of the trunk to engage a greater group of muscles in locomotion [9].

The study has attempted to show the impact of disorders of knee joint function on the quality of movement 

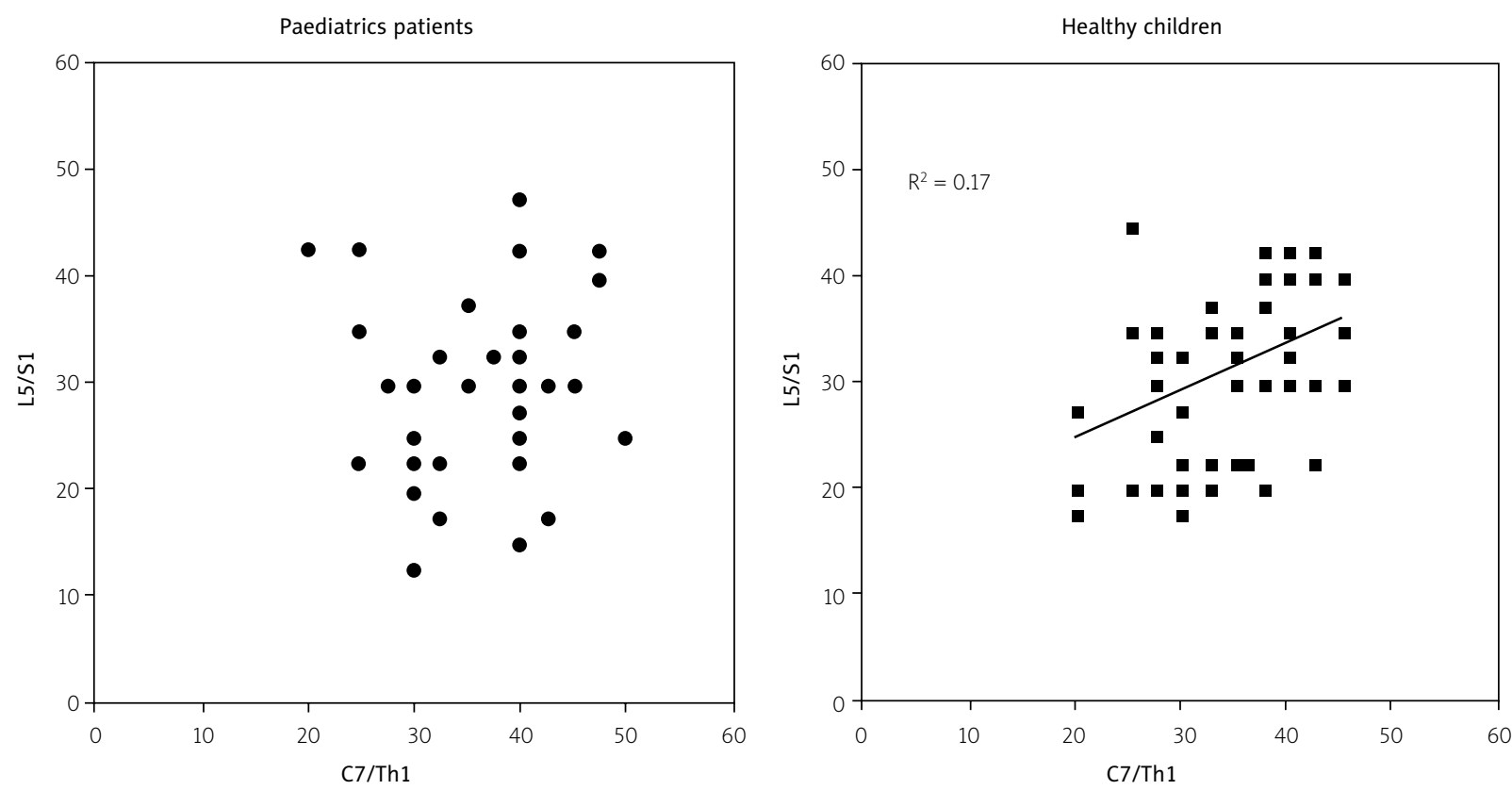

Fig. 2. Correlation between anteroposterior spinal curvatures in the two examined groups at the level of C7/Th1 and L5/S1.

in the adjacent joints and the changes to body position. It was difficult to select a homogeneous study group with involvement of a few or numerous joints, who met the inclusion and exclusion criteria. Therefore, the group of patients was not large. Empirical reports on pathomechanics of changes of articular JIA are based solely on small groups of juveniles [10-13].

The obtained results clearly show that changes that affect the knee joint, and that are the result of the change in the range of motion, have an impact on the functioning of the ankles and hip joints. It is the result of integrated musculofascial structures that form the entirety within the fascial system of the whole body $[9,13-16]$. Exudate to the cavity of the right knee joint and/or oedema enlarges clinically the outline of the knee. It causes tension of passive and active structures that stabilise the joint on its posterior, anterior and lateral surfaces of the lower extremity. Decreased and incorrect load of the extremity intensifies the shortening of the posterior kinematic chain in the shank and thigh area. The biarticular triceps surae, which controls active stabilisation of the knee, decreases the extensory function of the knee. It is achieved with the help of the gastrocnemius and soleus muscles. The soleus muscle, which is distally connected with the plantar fascia, tendons and venters of the short flexors of fingers through the calcaneal tuber, increases the range of plantar flexion, and decreases dorsal flexion in the lower tarsal joint.

Table III. Comparison of vertebral rotation in an erect position (Adam's forward bend test) in the two groups

\begin{tabular}{|lccc|}
\hline Erect position & $\begin{array}{c}\text { Paediatric patients } \\
n=36\end{array}$ & $\begin{array}{c}\text { Healthy children } \\
n=56\end{array}$ & $p$ \\
\hline The level of Th3 - to the left & $6(16.7 \%)$ & $7(12.5 \%)$ & NS \\
\hline The level of Th7 - to the left & $5(13.9 \%)$ & $5(8.9 \%)$ & NS \\
\hline The level of Th12 - to the left & $6(16.7 \%)$ & $7(12.5 \%)$ & NS \\
\hline The level of L2/3 - to the left & $5(13.9 \%)$ & $16(28.6 \%)$ & $<0.0005$ \\
\hline The level of Th3 - to the right & $11(30.6 \%)$ & $2(3.6 \%)$ & $<0.0001$ \\
\hline The level of Th7 - to the right & $15(41.7 \%)$ & $2(3.6 \%)$ & 0.0033 \\
\hline The level of Th12 - to the right & $13(36.1 \%)$ & $6(10.7 \%)$ & $<0.0001$ \\
\hline The level of L2/3 - to the right & $16(44.4 \%)$ & $2(3.6 \%)$ & . \\
\hline
\end{tabular}


Disturbed 3D construction of the flat-valgus foot puts the foot in pronation, reducing its dynamic function. Valgus position of the heel shortens the lateral band of the plantar fascia. Arthrosis of an elongated anterior tibial muscle and shortened long and short peroneal muscles, due to their place of attachment, transfer the tension from the anterolateral part of the shank to the area above the knee joint. Shortened peroneal muscles, which are attached to the head of the fibula, are connected through fascia to the musculus biceps femoris and lower fibres of the iliotibial band. Due to disorders in the articular capsule of the knee joint and the joint being kept in flexion, the head of the musculus biceps femoris becomes overactive. It pulls the fibula upwards and to the centre. Thus it may be responsible for external rotation of the tibial bone regarding the thigh, and may lead to the occurrence of valgity of the knees.

The connection of the fascial structures with the adductor magnus that runs under the remaining part of the musculus biceps femoris may lead to disturbed cooperation between the hip and knee joints or retroversion of the pelvis (through shortening of the ischiocrural muscles) $[15,16]$. The iliotibial band, which runs on a large area of the thigh - from the condyle of the tibia to the anterior and posterior superior iliac spines - is supported by the tensor of the broad fascia, the upper fibres of the gluteus maximus and gluteus medius. All this group of muscles plays a vital role in positioning of the lower extremity in external rotation. Also positioning of the left lower extremity in internal rotation in patients with right knee joint involvement is the effect of incorrect gait.

The influence of disorders of knee joint function on body position was evaluated in the present study also in children with right knee joint involvement and in children with left knee joint involvement. No correlation between deviations of posterior projection of the vertical and the occurrence of exudate and/or oedema of the joints, pain and positive Ober test was found. However, a positive correlation between the difference of dorsal flexion of the left and right foot and the difference of spinal curvatures at the level of C7/Th1 and L5/S1 was found. It is caused by altered elasticity of superficial musculofascial structures on the posterior part of the shank, thigh and vertebral column. Dorsal flexion restriction is related to excessive shortening of the triceps surae and the tension of the plantar fascia. According to Myers, they are both part of the superficial back line, and are connected structurally and functionally with the musculus biceps femoris. Hyperactivity of the musculus biceps femoris leads to the transfer of tension to the area of the ischiadic tuber, to which a strong pelvic ligament is attached. The sacrotuberous ligament transmits tension to the extensor muscle of the back and superficially on the sacral fascia. Thus, it directly impacts on the positioning of the pelvic girdle and physiological spinal curvatures. The presented way of transferring tension from the area of foot to the vertebral column explains the correlation observed in the present study $[9,15,16]$.

In order to emphasise the significance of disorders of knee joint function for the body position of the patients, dependence of the Ober test results and vertebral rotation were analysed. It was found that unilateral shortening of the iliotibial band induces rotation of the pelvis. The tension of the muscle group that accompanies the iliotibial band leads to the placement of the lower extremity in external rotation. Thus, the lower extremity is functionally elongated. The iliac ala on the examined side is placed in retroversion regarding the sacral bone. Therefore, in the sacroiliac joint nutation occurs. Then, while assessing the statics of the pelvis, lower positioning of the posterior superior iliac spine on the examined side is observed. This asymmetry - in the frontal and horizontal planes - has an effect on motion segments located in the upper part $[9,15,16]$.

The compensation mechanism that allows one to keep a vertical, firm body position consists in compensating the rotation of the pelvis in lower parts of the vertebral column. In the case of left knee joint involvement, which is accompanied by left-sided Ober sign, left-sided curve with rotation is observed in the lumbar part. According to Frayette's law, lateral bending of the lumbar spine is accompanied by vertebral rotation on the same side [9]. The results of the present study confirm this biomechanical principle, as we found a statistically significant correlation between the occurrence of the Ober sign in the left lower extremity and left-sided vertebral rotation at the level of $\mathrm{L} 2 / 3$.

Moreover, a statistically significant dependence $(p=$ $=0.0434$ ) between the occurrence of the Ober test and vertebral rotation in higher located segments of the vertebral column was found. Left-sided tension of the iliotibial band is also accompanied by vertebral rotation to the left at the level of Th12 and Th7. It may be caused by an irregular load of the lower extremities.

No similar analysis of the impact of knee disorders only on the movement of children with JIA has been found in the literature. Lechner et al. [14] basing on clinical interest on 144 patients made during routine medical visits drew attention to the existence of changes in the feet, depending on the duration and form of the disease. Broström with co-authors [17] in the analysis of differences between isometric and isokinetic strength of plantar flexion and dorsal feet found a significant reduction in the value of $u$ in a group of 10 girls with polyarthritis (compared to healthy subjects). Truckenbrodt [18] 
based on gait analysis of patients with the syndrome drew attention to the impact of changes in gait phases and the influence of destructive foot changes on gait phases and the need of individual physiotherapy to restore correct gait patterns. This comprehensive analysis of kinesiology of how to compensate for changes in the joints of the knee, made on the basis of research, does not require special equipment, mainly an improvement process [19-22].

\section{Conclusions}

1. The observed differences in the range and quality of motion in the ankle, hip and spinal joints between JIA patients and healthy children provide evidence that dysfunction of the knee joint affects the function of the other above-mentioned levels of the motor system.

2. Accumulation of microtrauma due to malcompensation in the motor system may lead to damage of the joints involved in the process.

The authors declare no conflict of interest.

\section{References}

1. Młodzieńcze idiopatyczne zapalenie stawów - nie tylko nowości. Rutkowska-Sak L (ed.). Termedia, Poznań 2014.

2. Ravelli A, Martini A. Juvenile idiopathic arthritis. Lancet 2007; 369: 767-778.

3. Żuk B, Księżopolska-Orłowska K. Usprawnianie stawu kolanowego $u$ małych dzieci chorych na młodzieńcze idiopatyczne zapalenie stawów. Reumatologia 2008; 48: 217-222.

4. Rutkowska-Sak L, Gietka P, Wierzbowska M, et al. Rheumatic diseases in the age of the child. Reumatologia 2012; 50: 142-161.

5. Amendt LE, Ause-Ellias KL, Eybers JL, et al. Validity and realibity testing of scoliometer. Physical Therapy 1990; 70: 108-117.

6. Seyfried A, Dudziński K. Badanie funkcjonalne narządu ruchu. In: Rehabilitacja medyczna. Kwolek A (ed.). Urban \& Partner, Wrocław 2003.

7. Kotwicki T. Badanie zakresu ruchu w stawach biodrowych modyfikacja techniki badania i wyniki pacjentów ze skoliozą. Ann Acad Med Siles 2007; 61: 35.

8. Kotwicki T, Frydryk K, Lorkowska M, et al. Powtarzalność i zdolność pomiaru rotacji tułowia skoliometrem Bunnella $u$ dziec ze skoliozą idiopatyczną. Fizjoter Pol 2006; 6: 111-116.

9. Neumann DA. Kinesiology of the Musculoskeletal System. Foundations for Rahabilitation. Mosoby Elsevier, Philadelphia 2010: 520-565.

10. Broström E, Nordlund MM, Cresswell AG. Plantar- and dorsiflexor strengh in prepuberal girls with juvenile idiopathic arthritis. Phys Med Rehabil 2004; 85: 1224-1230.

11. Ford K, Myer G, Melson P, et al. Land-Jump Performance in Patients with Juvenile Idiopathic Arthritis (IIA): A Comparison to Matched Controls. Intern J Rheum 2009, ID 478526:5 http:// dx.doi.org/10.1155/2009/478526.
12. Fairburn P, Panagamuwa B, Falkonakis A, et al. The use of multidisciplinary assessment and scientific measurement in advanced juvenile idiopathic arthritis can categorise gait deviations to guide treatment. Arch Dis Child 2002; 87: 160-165.

13. Spraul G, Koenning G. A descriptive study of foot problems in children with juvenile rheuatoid arthritis (JRA). Arthritis Rheum 1994; 7: 144-150.

14. Lechner DE, McCarthy CF, Holden MK. Gait deviations in patients with juvenile rheumatoid arthritis. Phys Ther 1987; 67: 1335-1341.

15. Myers WT. Anatomy Trains: Myofascial Meridians for Manual and Movement Therapists. Db Publishing, Warszawa 2010.

16. Myers WT. Structural integration - developments in Ida Rolf's "recipe" - Part 3. An alternative form. J Bodywork Movement Therapies 2004; 8: 249-264.

17. Broström E, Örtqvista M, Haglund-Åkerlinda Y, et al. Trunk and center of mass movements during gait in children with juvenile idiopathic arthritis. Human Movement Science 2007; 26: 296-305.

18. Truckenbrodt H, Häfner R, von Altenbockum C. Functional joint analysis of the foot in juvenile chronic arthritis. Clin Exp Rheumatol 1994; Suppl 10: S91-S96.

19. Dempster H, Porepa M, Young N, Feldman BM. The clinical meaning of functional outcome stores in children with juvenile arthritis. Arthritis Rheum 2001; 4: 1768-1774.

20. Broström E, Hagelberg S, Haglund-Akerlind Y. Effect of joint injections in children with juvenile idiopathic arthritis: evaluation by 3D-gait analysis. Acta Peadiatr 2004; 93: 906-910.

21. Hartmann M, Kreuzpointner F, Haefner R, et al. Effects of juvenile idiopathic arthritis on kinematics and kinetics of the lower extremities call of consequences in physical activities recommendations. Intern J Pediatr 2010; 10: 124-133.

22. Fairburn PS, Panagamuwa B, Falkonakis A, et al. The use multidisciplinary assessment and scientific measurement in advanced juvenile idiopathic arthritis can categories gait deviations to guide treatment. Arch Dis Child 2002; 87: 160-165. 